\title{
Control of pigeons' keypecking topography by a schedule of alternating food and water reward
}

\author{
MARCIA L. SPETCH, DONALD M. WILKIE, and RONALD W. SKELTON \\ The University of British Columbia, Vancouver, British Columbia V6T IW5, Canadu
}

\begin{abstract}
Food- and water-deprived pigeons keypecked for food or water reinforcement on alternate trials. Under one condition, explicit stimuli on the key provided information about the trial outcome; under another condition, only the alternation schedule provided this information. Latency and/or response rate differences between food- and water-rewarded trials emerged during both conditions. Response topography also differed on food-and water-rewarded trials. These differences, as revealed by duration and force measurements of the keypeck and by human ratings of the pecking responses as being water- or food-related, were anticipatory in nature. These results not only extend previous work on reward alternation and rewardspecific response topographies, but also have implications for theories of animal memory. In particular, these results are amenable to memory models that assume that an animal "codes" information that later must be recalled.
\end{abstract}

Reward alternation studies have provided good evidence that animals can remember the reward outcome of a trial and use this information as a discriminative stimulus. Capaldi and Stanley (1963), for example, exposed rats to alternating rewarded and nonrewarded runway trials, and observed the development of an appropriate alternation in running speedthe rats ran faster on rewarded trials than on nonrewarded trials. This effect occurred even when the trials were separated by 24 h (Capaldi \& Spivey, 1964).

Comparable results have been found for the barpress response. Rats barpressing during alternating rewarded and nonrewarded trials developed longer latencies to respond on nonrewarded trials (Gonzalez, Bainbridge, \& Bitterman, 1966; Wall \& Goodrich, 1964).

Apparently rats also can remember and use information about the type of reward as a discriminative stimulus. Pschirrer (1972) exposed rats to a sequence of three runway trial outcomes: either milk, pellets, and nonreward, or pellets, milk, and nonreward. Trials were separated by a 15 -min intertrial interval (ITI). The rats developed equally fast running speeds on milk- and pellet-rewarded trials, and slower speeds on nonrewarded trials. Pschirrer concluded that the slower running speeds on nonrewarded trials developed because one kind of reward served as a signal of reward on the following trial and the other kind

Supported by Natural Sciences and Engineering Research Council of Canada postgraduate scholarships (to Marcia L. Spetch and R. W. Skelton) and an operating grant (to Donald M. Wilkie). The assistance of L. Leader, R. Summers, D. King, B. Kirkbride, L. Terlecki, and D. Treit is gratefully acknowledged. Send reprint requests to Marcia L. Spetch, Department of Psychology, The University of British Columbia, Vancouver, B.C. V6T IW5, Canada. as a signal of nonreward. This interpretation received support from his second experiment, in which type of reward (milk or pellets) served as a discriminative stimulus for a right-left discrimination. Here, trials were separated by $3 \mathrm{~min}$ and the reward for a correct arm choice (milk or pellets) was determined randomly. Rats successfully learned to choose between a left or right alley on the basis of the type of reward received on the preceding trial.

In these and other reward alternation studies, the usual behavioral measure of discrimination has been speed of running in an alley or latency to barpress. One measure that has not been studied is response topography.

It has been demonstrated recently that the topography of an animal's response to a stimulus signaling reward will vary for different types of reward. For example, Jenkins and Moore (1973) studied pigeons' autoshaped responding to keys that signaled grain or water, and found that responses to the key signaling water resembled drinking movements, whereas responses to a key signaling grain resembled eating movements. Similar differences in the form of pigeons' keypecks for food or water reward were reported by Wolin (1964). Using rats, Hull (1977) found topographical differences in food- and water-rewarded barpresses: rats responding for food reward made more long-duration presses than did rats responding for water reward, and judges were able to identify correctly the reward for which the rats were pressing.

The present experiment was designed both to extend previous investigations of the discriminative properties of past rewards and to provide more information on the variables controlling response topography. While the above topography studies have demonstrated control over the form of responses by 
an external stimulus unambiguously related to a single reward type, and while the alternation studies have demonstrated control over other response properties (speed and latency) in the absence of such explicit predictive stimuli, topography analyses in reward alternation paradigms have not yet been done. In the present study, pigeons were exposed to a schedule of alternating food and water reward and keypeck topography was observed.

\section{EXPERIMENT 1}

\section{Method}

\section{Subjects}

Three experimentally naive Silver King pigeons were deprived to $80 \%$ of normal weight, and then maintained at this weight by food obtained during and after daily sessions and water obtained during the sessions. Bird 1 received $9 \mathrm{ml}$ of water per day; Birds 2 and 3 received $16 \mathrm{ml}$ per day. Health grit was available continuously in the large individual home cages.

\begin{abstract}
Apparatus
A BRS-Foringer Model PS-004 one-key pigeon chamber was used. A modified chamber door with a circular opening $10 \mathrm{~cm}$ in diameter permitted closed-circuit TV viewing of the pecking key area. The BRS/LVE Model 121-16 clear-plastic pecking key, which required a force of about $.2 \mathrm{~N}$, was located on the center of one wall. An Industrial Electronics Engineers' Series 10 stimulus projector, equipped with 4.8-W lamps, was mounted behind the key and illuminated the key with a uniform field of yellow light. It also projected a $2.54 \times .32 \mathrm{~cm}$ white line, with a 0 or $90 \mathrm{deg}$ orientation, on to the yellow field in certain stages of the experiment. The houselight consisted of two constantly illuminated 4.8-W lamps mounted behind a metal reflector in the upper front corners of the chamber. A fan ventilated the chamber and created a masking noise.
\end{abstract}

A BRS/LVE Model 141-10 solenoid-operated grain feeder, which allowed timed access to mixed grain, was located directly below the key. Feeder operations were accompanied by illumination of a 4.8-W lamp in the hopper. A BRS/LVE Model 114-06 solenoidoperated valve dispensed $\mathrm{I} \mathrm{ml}$ of water into a plastic container, $31 / 2 \mathrm{~cm}$ in diameter, mounted on the wall to the left of the feeder. Water presentations were accompanied by illumination of a 4.8-W lamp mounted on the wall $3 \mathrm{~cm}$ to the left of the water receptacle. A Sony camera, videorecorder, and monitor were used to view and record keypecks.

\section{Procedure}

Preliminary training. The subjects were trained to eat from the hopper and drink from the water container during two initial sessions. Then keypecking was established by an autoshaping procedure in which the key was lit with yellow light for $5 \mathrm{sec}$ followed by food and water on alternate trials. Trials were separated by a 30 -sec ITI. When reliable keypecking had developed, the birds were exposed to a response-contingent fixed interval (FI) 30-sec schedule, under which food and water reward alternated. During several preliminary sessions with this procedure, eating and drinking behaviors were monitored, and parameters, such as reward magnitude and the number of trials per session, were modified until the birds reliably consumed each reward with a latency of less than $1.0 \mathrm{sec}$ and showed no indication of satiation to either type of reward during a session. Once these criteria were reached, the experiment proper was begun.

Experiment proper. The birds' keypecking continued to be rewarded according to a response-contingent FI 30-sec schedule, with a 5-sec ITI (key light off) between reinforcement of fset and onset of the next FI. Successive FIs therefore were considered to be trials separated by a 5-sec ITI. Trials ended with either food reward, consisting of 4-sec illumination of the hopper and access to mixed grain, or water reward, consisting of 5-sec illumination of the water receptacle and $1 \mathrm{ml}$ of water. During all sessions, food- and water-rewarded trials alternated, and the reward presented on the first trial of the session was varied randomly. The number of trials in each session was fewer than the number of rewards required to satiate each bird, as determined during preliminary training. Bird 1 generally received 18 trials per day; Birds 2 and 3 received 32 trials per day. The number of keypecks during food trials and water trials was recorded, but the data from the first two trials of each session were discarded. Sessions were conducted every day at about the same time.

Each bird served under two conditions that differed with respect to the stimuli signaling reward outcome on a given trial. Under Condition $U$ (unsignaled reward alternation), the pecking key was illuminated with the same stimulus (yellow light) during both food-rewarded and water-rewarded trials. Thus, only the alternation schedule itself provided information about the trial outcome. Under Condition S (signaled reward alternation), trial outcome was signaled by a key stimulus as well as by the alternation schedule. During food-rewarded trials, a 90-deg white line was superimposed on the yellow background; during waterrewarded trials, a 0-deg white line was superimposed on the yellow key. All birds were exposed first to Condition $U$ and then to Condition S. Bird 1 served under both conditions twice; Birds 2 and 3 were exposed to each condition three times. Each condition was in effect for several (4 to 40) sessions at a time.

Keypecking was videotaped during randomly selected trials of randomly selected sessions from each condition. The filming angle prevented the videorecording of the stimulus on the key and the trial outcome, but these were noted by the experimenter. Videorecording on a trial began with the first keypeck after $10 \mathrm{sec}$ of the FI had elapsed.

The video tapes were rated by three judges, who were unaware of the experimental condition ( $U$ or $S$ ) and the reward outcome. Each judge was familiar with the literature on response topography and, in particular, with Jenkins and Moore's (1973) description of pigeons' pecking topographies to signals of food and water. Ratings were conducted in four 2-h sittings. At the start of each sitting, the judges were shown a sample of keypecks for food reward and keypecks for water reward taken from representative trials during Condition $\mathrm{S}$. [These samples were consistent with the description of pecking topographies provided by Jenkins and Moore (1973). Pecks for food generally were openbeaked, forceful, and of short duration, whereas pecks for water were characterized by sustained, less forceful key contacts with closed beaks or "mumbling" movements.] Thereafter, recorded trials from signaled and unsignaled sessions were shown to the judges in a mixed order. The judges were asked to rate each trial by indicating whether they thought "food-type" or "water-type" pecks predominated. These ratings were scored as correct when the judges' indication of food- or water-related pecks matched the reward outcome of the trial.

\section{Results and Discussion}

The mean accuracy of the judges in rating keypeck topography was above chance level $(50 \%)$ during both the unsignaled and the signaled conditions. During Condition $U$, the judges were correct on $56 \%$, $68 \%$, and $69 \%$ of the trials for Birds 1, 2, and 3, respectively; during Condition $\mathrm{S}$, the judges were correct on $94 \%, 88 \%$, and $93 \%$ of the trials. These results suggest that explicit signals for type of reward are not necessary for the emergence of reward- 
appropriate pecking topography; during unsignaled reward alternation, anticipatory food- and water-type pecks emerged in the absence of explicit signals for reward type. Such signals, however, may enhance topography differentiation; the judges were more accurate in rating topography during the signaled condition.

Differences in rate of pecking on food- and waterrewarded trials also emerged in both conditions; the mean number of pecks per second on water trials (38.03) was greater than on food trials (26.12). (These rate differences may reflect differences in latency to start pecking- see Experiment 2).

A two-way repeated-measures analysis of variance confirmed that rate of pecking on water-rewarded trials was greater than that on food-rewarded trials $[F(1,2)=59.04, p<.05]$. There was no significant effect of conditions $[F(1,2)=.01, p>.05]$, and there was no significant Trial Outcome by Condition Interaction $[F(1,2)=5.06, \mathrm{p}>.05]$.

The difference in rate of pecking on the two types of trials provides additional evidence that keypecking was controlled by the alternating reward schedule, and is consistent with previous studies that have demonstrated control of quantitative aspects of responding by schedules of reward alternation (e.g., Pschirrer, 1972).

\section{Experiment 2}

This experiment was designed to provide a more detailed analysis of the rate and topographical differences in pigeons' keypecking on food- and waterrewarded trials under reward alternation schedules. Pigeons were exposed to signaled and unsignaled schedules of alternating food and water rewards, and keypecking on food-and water-rewarded trials was analyzed in terms of four measures: latency to first peck; rate of pecking during the period following the first peck; duration of the penultimate peck; and force of the penultimate peck. Birds were exposed also to an unsignaled random schedule of food and water rewards as a control condition to assess the possible effects of reward type on keypecking during the subsequent trial. Under this condition, keypecking was analyzed on trials that followed water rewards and trials that followed food rewards. Finally, keypecking was videorecorded during sessions from the alternating and random conditions, and the topographies were rated by judges.

\section{Method}

\section{Subjects}

The subjects were six naive Silver King pigeons (Birds 1, 2, 4, 5, 6, and 7) and one White King pigeon (Bird 3) with an extensive experimental history. All birds were food- and waterdeprived to $80 \%$ of their normal weights and maintained at these weights by mixed grain and 20 to $25 \mathrm{ml}$ of water obtained during and after the daily experimental sessions. The subjects were housed in large individual cages with grit freely available.

\section{Apparatus}

The test chamber was a ventilated picnic cooler containing a 4.8-W shielded lamp that provided general illumination, a BRS/ LVE Model 141-10 grain feeder, a BRS/LVE Model 114-06 water dispenser, a BRS/LVE Model 121-16 pecking key, and a BRS/ LVE Model 111-05 tricolor stimulus projector. The shielded lamp was mounted in the upper left-hand corner of one wall. The grain feeder was centered on this wall, and the water dispenser was mounted to the right of the grain feeder. The key was mounted behind a $25-\mathrm{mm}$ circular opening above the grain feeder, and the projector was mounted behind the key. The standard microswitch was removed from the pecking key and replaced with three pecksensing switches (see Skelton, Spetch, \& Wilkie, 1980, for details). These switches were set to detect pecks with minimum forces of $.10, .22$, and $.61 \mathrm{~N}$. This permitted a separation of pecks into three force categories: .10 to $.22 \mathrm{~N}, .22$ to $.61 \mathrm{~N}$, and greater than $.61 \mathrm{~N}$.

Control of experimental conditions and collection of data were performed by a Data General Nova 3 computer. A Sony camera, videorecorder, and monitor were used to record and view keypecks.

\section{Procedure}

Preliminary training. The naive pigeons were trained first to eat from the hopper and drink from the water receptacle and then were exposed to autoshaping sessions in which a 5 -sec illumination of the center key was followed alternately by grain or water presentations. Each bird then was exposed to a few sessions in which the procedure was the same as that used during the initial conditions of the experiment proper (see below). During this time, the force levels on the key were adjusted to ensure that differences in force on food and water trials would be detected.

Experiment proper. All sessions consisted of 30 trials separated by a 5 -sec ITI (key light off). Each trial began with illumination of the pecking key, and a tandem fixed time (FT) 25-sec fixed ratio (FR) 2 schedule was initiated. (Alternately, the schedule may be classified as a FI 25 -sec schedule requiring two pecks for reinforcement.) Completion of the schedule resulted in 5-sec illumination of the hopper and access to mixed grain on 15 trials; on the remaining 15 trials, completion of the schedule resulted in 5 -sec illumination of the water receptacle and presentation of $1 \mathrm{ml}$ of water. The order of food and water trials, and the color of the illuminated pecking key on each, depended upon the condition. Under Condition $U$ (unsignaled), the reward type of the first trial in each session was determined randomly, but thereafter foodand water-rewarded trials alternated. The pecking key was illuminated with the same stimulus (white light) on both types of trials. Under Condition S (signaled), food- and water-rewarded trials occurred in an alternating order, but the pecking key was illuminated with different stimuli (red on food trials and green on water trials for some birds; green on food trials and red on water trials for others) on the two types of trials. There was a third treatment, Condition $\mathrm{R}$ (unsignaled random), under which the order of food-and water-rewarded trials was determined randomly, with the restriction that each type of trial occur 15 times in each session. The pecking key was illuminated with the same stimulus (yellow light) on both types of trials.

The birds were tested for several sessions (20 to 110) at a time under these conditions. Birds 1, 2, and 3 were exposed first to Condition $S$ and then to Condition U. Because of illness, these birds were not tested under Condition $R$. The remaining four birds each served twice under Conditions $S$ and $U$, and once under Condition $R$. The order of exposure to these conditions was $S, U$, $S, U, R$, for Bird 4, and U, S, U, S, R for Birds 5, 6, and 7 .

$A$ keypeck was defined as the opening and closing of the most sensitive $(.10 \mathrm{~N})$ switch. Keypecking during the last 28 trials of each session was analyzed in terms of latency, rate, force category, and duration. During Conditions $S$ and $U$, keypecking on foodand water-rewarded trials was compared; during Condition $R$, 
keypecking on trials that followed a food reward was compared with keypecking on trials that followed a water reward.

Latency and rate measures were taken from the FT component of the tandem schedule. The time from illumination of the pecking key until the first peck (operation of the .10-N switch) defined latency; if no pecks occurred during this component of the schedule, a value of $25 \mathrm{sec}$ was assigned as the peck latency. The rate of keypecking then was calculated by dividing the number of pecks (operations of the $.10-\mathrm{N}$ switch) by the time remaining in the FT component (i.e., $25 \mathrm{sec}$ minus the latency).

The analysis of response topography was conducted on the first required peck of the FR component of the tandem schedule. By selecting a single peck for topographical analysis, we equated the number of pecks analyzed on food-and water-rewarded trials. The last peck was not chosen because of the possibility that presentation of the reward might influence the topography of this peck. Peck duration was measured as the time between opening and closing of the peck-sensing switch with the lowest minimum force requirement $(.10 \mathrm{~N})$. Peck force was analyzed by separating pecks into one of three force categories, on the basis of which of the three peck sensing switches were operated by the peck. Pecks that operated only Switch 1 had a peak force of between .10 and $.22 \mathrm{~N}$; these were assigned to Category 1. Pecks that operated Switches 1 and 2, but not Switch 3, had a peak force of between .22 and $.61 \mathrm{~N}$ and were assigned to Category 2 ; pecks that operated all three switches had a peak force of greater than $.61 \mathrm{~N}$ and were assigned to Category 3. (Additional details on these measurement procedures are found in Skelton et al., 1980).

Randomly selected trials from two sessions of Conditions $U$, $S$, and $R$ were videotaped for Birds $4,5,6$, and 7 , and their keypeck topographies were rated by two judges who had had no previous experience in analyzing peck topographies. The procedure used for filming and rating keypecks was the same as that described in Experiment 1. Ratings of keypecks from Conditions $\mathrm{U}$ and $\mathrm{S}$ were marked correct when the judges' responses of foodor water-related topographies matched the reward outcome of the trial. Ratings of keypecks from Condition $R$ were marked correct when the indicated topography did not match the reward type of the preceding trial (i.e., "water" was scored as a correct choice after a food trial, and vice versa). Thus, high rating accuracies in Condition $\mathbf{R}$ would occur if the birds made food-type pecks after water and water-type pecks after food, regardless of whether food predicted water or vice versa.

\section{Results and Discussion}

Differences in keypecking on food- and waterrewarded trials emerged during both the signaled and unsignaled reward alternation conditions. Latency to start pecking generally was longer on water-rewarded trials than on food-rewarded trials; some birds also showed consistent differences in rate of pecking on food- and water-rewarded trials, but the direction of these rate differences was not consistent across birds. Longer duration keypecks were made on waterrewarded trials than on food-rewarded trials by all birds except one; however, this bird showed a clear difference in peck force, making more forceful pecks on food-rewarded trials. Four other birds also made more forceful pecks on food-rewarded trials than on water-rewarded trials; two birds did not show consistent differences in peck force.

These differences in keypecking were not maintained when the birds were exposed to the random schedule of food and water trials; differences in keypecking on trials that followed food and trials that followed water decreased or disappeared with exposure to the random schedule.

Judges who viewed videotaped segments of the pigeons' keypecking were able to identify correctly keypecks made on food-and water-rewarded trials during both the signaled and unsignaled reward alternation conditions. The judges' ratings of peck topographies were not related to the reward type of the preceding trial during the random condition.

These findings are discussed in detail in the following sections.

\section{Latency and Rate}

Mean latency to first peck was significantly shorter on food-rewarded trials than on water-rewarded trials under Condition $U$ [5.16 sec on food trials, $9.96 \mathrm{sec}$ on water trials; $\mathfrak{t}(6)=2.99, \mathrm{p}<.05]$ and Condition $\mathrm{S}$
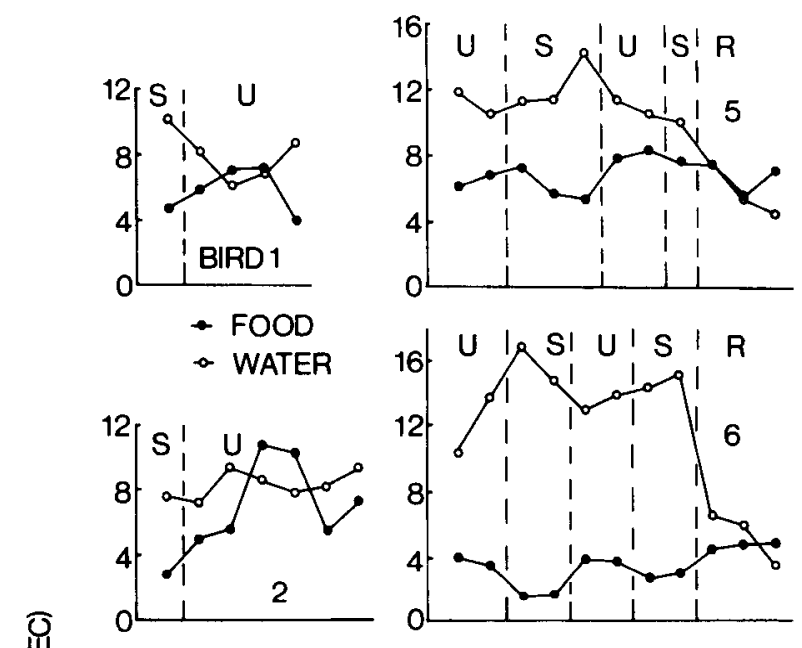

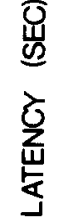
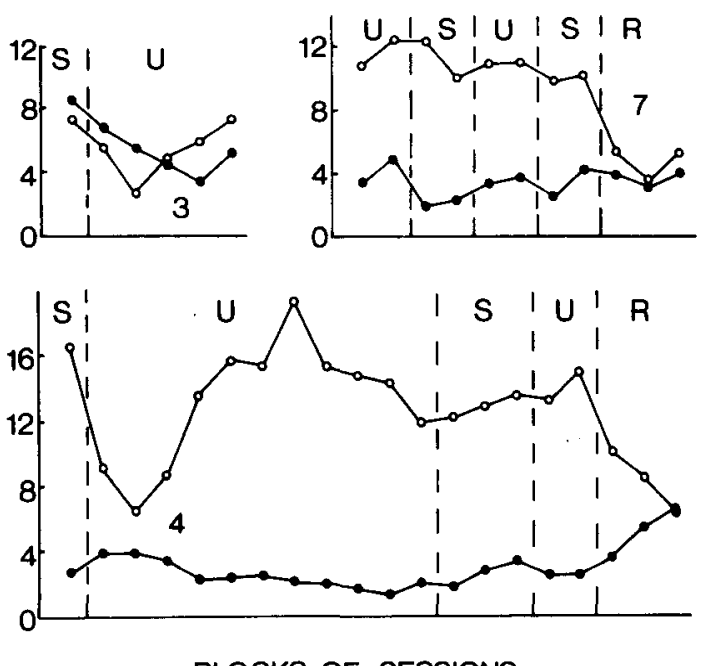

BLOCKS OF SESSIONS

Figure 1. Latency to first peck on food- and water-rewarded trials in the unsignaled (U), signaled (S), and random $(R)$ conditions of Experiment 2. Scores are averages of 10-session blocks. See text for details. 
[4.28 sec on food trials, $10.83 \mathrm{sec}$ on water trials; $\mathrm{t}(6)=3.68, \mathrm{p}<.05]$, but not under Condition $R$ [6.1 sec on trials following food, $5.4 \mathrm{sec}$ on trials following water; $t(3)=1.28, p>.05]$.

The latency scores of individual subjects for blocks of 10 sessions during each condition are shown in Figure 1. Two aspects of these data are noteworthy: first, the consistency of the latency differences on food and water trials over sessions, especially for Birds 4, 5, 6, and 7, and, second, the disappearance of these differences during Condition $\mathrm{R}$. These results provide evidence for the anticipatory nature of the bird's responding; latency differences occurred only when the type of reward on each trial was signaled, or predicted by the type of reward on the preceding trial.

Rate of pecking was less sensitive to the reward alternation schedule than was latency to initial peck. Although five of the birds showed consistent differences in rate of pecking on food and water trials under both Condition $\mathrm{S}$ and Condition $\mathrm{U}$, the direction of these differences varied between subjects. Consequently, the mean rates of pecking on food and water trials were not significantly different during any condition [Condition $U$, mean pecks $/ \mathrm{sec}=2.14$ on food trials, 2.05 on water trials; $t(6)=.604, p>.05$; Condition S, mean pecks $/ \mathrm{sec}=2.07$ on food trials, 2.28 on water trials; $\mathrm{t}(6)=.604, \mathrm{p}>.05$; Condition $\mathrm{R}$, mean pecks $/ \mathrm{sec}=1.78$ on trials following food, 1.81 on trials following water; $t(3)=.644, p>.05$ ].

\section{Peck Topography: Duration and Force}

Peck duration was shorter on food-rewarded trials than on water-rewarded trials during both Condition $U$ [mean $=35.8 \mathrm{msec}$ on food trials, $43.3 \mathrm{msec}$ on water trials; $\mathrm{t}(6)=3.35, \mathrm{p}<.05]$ and Condition $\mathrm{S}$ [mean $=37.2 \mathrm{msec}$ on food trials, $50.7 \mathrm{msec}$ on water trials; $\mathrm{t}(6)=2.53, \mathrm{p}<.05$ ]. However, these differences were not maintained during Condition $R$ [mean peck duration $=36.8 \mathrm{msec}$ on trials following food, $37.3 \mathrm{msec}$ on trials following water; $\mathrm{t}(3)=.577$, $\mathrm{p}>.05]$.

Data on peck duration are shown for individual subjects during blocks of 10 sessions in Figure 2. Keypeck durations were consistently longer on water trials during both Condition $\mathrm{S}$ and Condition $\mathrm{U}$ except for Bird 6, which tended to make slightly longer pecks on food trials throughout the experiment. Again, the disappearance of peck duration differences during Condition $R$ for Birds 4,5 , and 7 provides evidence that the differences in peck duration were controlled by the alternating schedule of rewards.

Table 1 shows the mean percentage of pecks falling within the three force categories for each bird in each condition. For most birds, keypecks were more forceful on food trials than on water trials during both Condition S and Condition U; more category 1
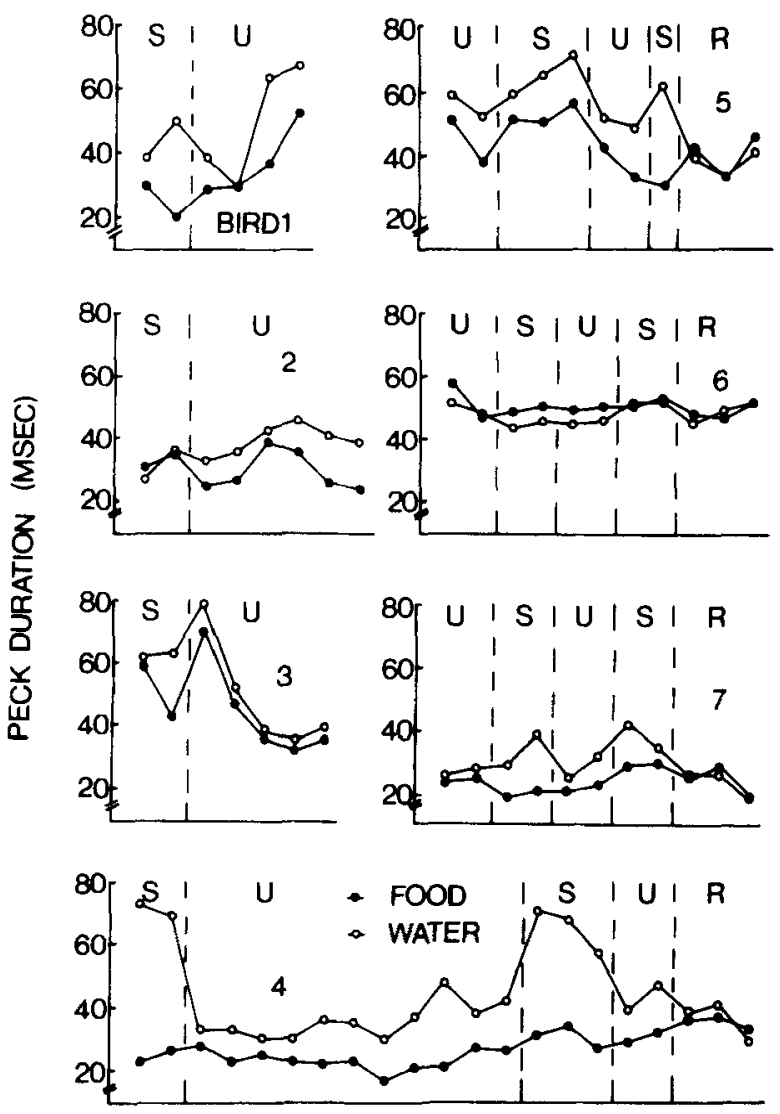

BLOCKS OF SESSIONS

Figure 2. Peck duration on food- and water-rewarded trials in the unsignaled (U), signaled (S), and random (R) conditions of Experiment 2. Scores are averages of 10 session blocks. See text for details.

and category 2 pecks were made on water trials, whereas more category 3 pecks were made on food trials. Bird 7, however, showed this pattern only during Condition $\mathrm{S}$, and Bird 4 did not peck more forcefully on food trials during either condition. It is worth noting that the one subject (Bird 6) that did not show differences in peck duration showed clear differences in keypecking force on food and water trials during both Condition $\mathrm{S}$ and Condition $\mathrm{U}$. Thus, all birds showed a difference in either duration or force, or both, under both signaled and unsignaled reward alternation schedules.

An analysis of variance on the force data revealed a significant main effect of trial type on percentage of category 2 pecks $[F(1,6)=12.27, p<.05]$ and category 3 pecks $[F(1,6)=7.69, p<.05]$, as well as a significant Trial Type by Condition interaction for category $2[F(2,9)=35.71, p<.05]$ and category 3 pecks $[F(2,9)=18.20, p<.05]$. These effects were not significant for category 1 pecks. Duncan's multiple range tests with alpha set to .05 revealed 
Table 1

Mean Percentage of Pecks in Each Force Category on Food (F) and Water (W) Trials

\begin{tabular}{|c|c|c|c|c|c|c|}
\hline \multirow[b]{3}{*}{ Bird } & \multicolumn{6}{|c|}{ Force Category } \\
\hline & \multicolumn{2}{|c|}{1} & \multicolumn{2}{|c|}{2} & \multicolumn{2}{|c|}{3} \\
\hline & $\mathrm{F}$ & W & $\mathrm{F}$ & W & $F$ & W \\
\hline & \multicolumn{6}{|c|}{ Condition $\mathbf{U}$} \\
\hline $\begin{array}{l}1 \\
2 \\
3 \\
4 \\
5 \\
6 \\
7\end{array}$ & $\begin{array}{r}1.3 \\
6.2 \\
4.6 \\
18.5 \\
3.3 \\
1.6 \\
11.8\end{array}$ & $\begin{array}{r}3.1 \\
6.6 \\
6.4 \\
15.4 \\
9.0 \\
3.0 \\
9.5\end{array}$ & $\begin{array}{r}2.3 \\
22.8 \\
20.2 \\
28.3 \\
19.8 \\
2.8 \\
26.5\end{array}$ & $\begin{array}{r}3.5 \\
24.6 \\
23.6 \\
30.4 \\
25.5 \\
8.3 \\
27.0\end{array}$ & $\begin{array}{r}46.4 \\
21.0 \\
25.2 \\
3.2 \\
26.9 \\
45.8 \\
11.8\end{array}$ & $\begin{array}{r}43.5 \\
18.8 \\
20.0 \\
4.2 \\
15.6 \\
38.5 \\
13.5\end{array}$ \\
\hline Mean & 6.8 & 7.6 & 17.5 & 20.4 & 25.8 & 22.1 \\
\hline $\begin{array}{l}1 \\
2 \\
3 \\
4 \\
5 \\
6 \\
7\end{array}$ & $\begin{array}{r}2.9 \\
.8 \\
2.8 \\
17.9 \\
3.3 \\
.8 \\
8.4\end{array}$ & $\begin{array}{r}5.2 \\
21.2 \\
9.8 \\
16.4 \\
11.1 \\
2.3 \\
11.0\end{array}$ & $\begin{array}{r}\text { Cond } \\
.6 \\
5.6 \\
14.8 \\
25.6 \\
15.2 \\
1.6 \\
25.8\end{array}$ & $\begin{array}{l}\text { on S } \\
16.4 \\
25.4 \\
34.0 \\
30.0 \\
27.9 \\
8.8 \\
28.6\end{array}$ & $\begin{array}{r}46.6 \\
43.7 \\
32.6 \\
6.3 \\
31.7 \\
47.8 \\
15.8\end{array}$ & $\begin{array}{r}29.5 \\
3.5 \\
6.2 \\
3.6 \\
11.1 \\
39.1 \\
9.5\end{array}$ \\
\hline \multirow[t]{2}{*}{ Mean } & 5.3 & 10.9 & 12.8 & 24.4 & 32.1 & 14.6 \\
\hline & \multicolumn{6}{|c|}{ Condition $\mathbf{R}$} \\
\hline $\begin{array}{l}4 \\
5 \\
6 \\
7\end{array}$ & $\begin{array}{r}6.9 \\
2.6 \\
.5 \\
9.7\end{array}$ & $\begin{array}{r}4.9 \\
2.1 \\
.3 \\
9.9\end{array}$ & $\begin{array}{r}29.2 \\
11.8 \\
1.0 \\
32.8\end{array}$ & $\begin{array}{r}28.4 \\
14.8 \\
.6 \\
30.1\end{array}$ & $\begin{array}{r}13.8 \\
35.7 \\
48.5 \\
7.6\end{array}$ & $\begin{array}{l}16.7 \\
33.1 \\
49.1 \\
10.0\end{array}$ \\
\hline Mean & 4.9 & 5.3 & 18.7 & 18.5 & 26.4 & 27.2 \\
\hline
\end{tabular}

that the percentage of category 2 pecks was significantly different on food and water trials during Conditions $\mathrm{S}$ and $\mathrm{U}$, but not during Condition $\mathrm{R}$; the percentage of category 3 pecks was significantly different on food and water trials during Condition $\mathrm{S}$ only.

\section{Rating of Keypeck Topographies}

Table 2 shows the judges' mean accuracy in rating keypeck topographies of the four birds during the three conditions. Two results are apparent. First, the judges were able to identify correctly keypecks from food-rewarded and water-rewarded trials during both Condition S and Condition U. Second, the judges' rating of peck topography was not related to the reward type of the preceding trial during Condition $\mathbf{R}$.

Table 2

Judges' Mean Rating Accuracy of Keypeck Topography During Experiment 2

\begin{tabular}{crcccc}
\hline & \multicolumn{5}{c}{ Bird } \\
\cline { 2 - 6 } $\begin{array}{c}\text { Condi- } \\
\text { tion }\end{array}$ & 4 & 5 & 6 & 7 & Mean \\
\hline $\mathrm{U}$ & 86 & 92 & 73 & 92 & 86 \\
$\mathrm{~S}$ & 100 & 98 & 90 & 100 & 97 \\
$\mathrm{R}$ & 65 & 48 & 60 & 44 & 54 \\
\hline
\end{tabular}

These observations were confirmed by statistical analysis: a two-way repeated measures analysis of variance revealed a significant main effect of conditions $[F(2,3)=58.29, p<.05]$, and a Duncan's multiple range test with alpha set to .05 revealed that accuracy was significantly higher during both Conditions $\mathrm{S}$ and Condition $\mathrm{U}$ than during Condition $\mathrm{R}$. The difference in accuracy between Conditions $\mathrm{S}$ and $\mathrm{U}$ was not significant.

The ability of the judges to identify food- and waterrelated pecks during both of the reward-alternation conditions, but not the random condition, provides further evidence that the peck topographies were anticipatory and controlled by the alternating schedule.

\section{GENERAL DISCUSSION}

Clearly, pigeons develop anticipatory, rewardappropriate pecking topographies under schedules of alternating food and water rewards, in the absence of explicit signals for reward type. During the unsignaled alternation condition, pigeons keypecked during foodand water-rewarded trials with topographies similar to those made to explicit signals of food and water and identifiable to human observers as being foodand water-related, respectively. In general, keypecking was characterized by short-duration, forceful pecks on food-rewarded trials, and longer, less forceful pecks on water-rewarded trials. These differences in keypecking on food- and water-rewarded trials are consistent with the reports of Jenkins and Moore (1973) and Wolin (1969). The present study is unique in showing such differences in keypecking in the absence of explicit external stimuli signaling food and water.

The quantitative differences in keypecking on the alternating food and water trials during the unsignaled alternation condition provided further evidence that responding was controlled by the alternating schedule. The results of Experiment 2 suggested that differences in latency might be more susceptible to control by the alternating schedule than are differences in rate of pecking.

These results also extend the previous work on reward alternation learning. The quantitative differences in pigeons' keypecking on alternate food- and waterrewarded trials are consistent with the results of previous reward-alternation studies with rats. The anticipatory peck topographies found here extend the previous studies by showing that qualitative (i.e., topographical) aspects of responding also can be controlled by an alternating schedule.

A common interpretation of reward alternation learning is that animals remember the last reward received, and that this memory controls responding on the next trial (e.g., Bolles, 1976; Capaldi \& Spivey, 1964). The anticipatory pecking topographies found 
in the present study have implications for the form such a memory might take. A view of memory as a "stimulus trace" (e.g., Roberts \& Grant, 1976) would have the pigeon remembering food while making water-type pecks, and vice versa-a somewhat paradoxical phenomenon. The present findings seem to be more amenable to recent "coding" or "instructional" views of memory (e.g., Carter \& Werner, 1978; Honig, 1978). These views suggest that discriminative stimuli are coded or transformed by the animal in a way that retains the information value but not necessarily the physical properties of the stimuli. Memories of these transformed stimuli then control subsequent behavior. Accordingly, in the present experiment, if pigeons coded food as "water next" and remembered "water next" on the following trial, and vice versa, the anticipatory pecking topographies would be expected.

\section{REFERENCES}

Bolles, R. C. Some relationships between learning and memory. In D. L. Medin, W. A. Roberts, \& R. T. Davis (Eds.), Processes of animal memory. Hillsdale, N.J: Erlbaum, 1976.

Capaldi, E. J., \& Spivey, J. E. Stimulus consequences of reinforcement and nonreinforcement: Stimulus traces of memory. Psychonomic Science, 1964, 1, 403-404.

Capaldi, E. J., \& Stanley, L. R. Temporal properties of reinforcement aftereffects. Journal of Experimental Psychology, $1963,65,169-175$.
Carter, D. E., \& Werner, T. J. Complex learning and information processing by pigeons: A critical analysis. Journal of the Experimental Analysis of Behavior, 1978, 2, 565-601.

Gonzalez, R. C., Bainbridge, P., \& Bitterman, M. E. Discretetrials lever pressing in the rat as a function of pattern reinforcement, effortfulness of response, and amount of reward. Journal of Comparative and Physiological Psychology, 1966, 61, 110-122.

HoNIG, W. K. Studies of working memory in the pigeon. In S. H. Hulse, H. Fowler, \& W. K. Honig (Eds.), Cognitive processes in animal learning. Hillsdale, N.J: Erlbaum, 1978.

HuLl, J. H. Instrumental response topographies of rats. Animal Learning \& Behavior, 1977, 5, 207-212.

Jenkins, H. M., \& Moore, B. R. The form of the auto-shaped response with food or water reinforcers. Journal of the Experimental A nalysis of Behavior, 1973, 20, 163-181.

Pschirrer, M. Goal events as discriminative stimuli over extended intertrial intervals. Journal of Experimental Psychology, 1972, 96, 425-432.

Roberts, W. A., \& Grant, D. S. Studies of short-term memory in the pigeon using the delayed matching to sample procedure. In D. L. Medin, W. A. Roberts, \& R. T. Davis (Eds.), Processes of animal memory. Hillsdale, N.J: Erlbaum, 1976.

Skelton, R. W., Spetch, M. L., \& Wilkie, D. M. A method for automatically recording topographical differences in pigeons' keypecking for food and water reinforcers. Behavior Research Methods \& Instrumentation, 1980, 12, 349-352.

WALL, A. M., \& Goodrich, K. P. Differential responding on reinforcement and nonreinforcement trials occurring in fixed repeated patterns. Psychonomic Science, 1964, 1, 193-194.

Wolin, B. R. Difference in manner of pecking a key between pigeons reinforced with food and water. In A. C. Catania (Ed.), Contemporary research in operant behavior. Glenview, IIl: Scott, Foresman, 1968.

(Received for publication June 4, 1980; revision accepted October 18,1980 .) 